\title{
PENGARUH IMPLEMENTASI BALANCED SCORECARD TERHADAP KINERJA PERUSAHAAN PADA PT GRAMEDIA ASRI MEDIA
}

\author{
Muhammad Fajar Kamal \\ Program Studi Magister Manajemen Universitas Tarumanagara \\ fajarkamal03@gmail.com \\ Nurahma Tresani \\ Program Studi Magister Manajemen Universitas Tarumanagara \\ ntresani@gmail.com
}

\begin{abstract}
This study aims to determine the effect of implementation scorecard that divided into 4 perspectives, it called financial perspective, customer perspective, perspective internal business processes, and learning \& growth perspective on the performance of PT. Gramedia Asri Media. PT Gramedia Asri Media is a company of retail industry. The method used in this study is a survey with an associative type of research. The analysis starts with collecting data obtained from the distribution of questionnaires with the intended analysis unit, namely the store manager of PT Gramedia Asri Media. The data obtained is processed using the SPSS 20 application with simple regression analysis techniques and multiple regression. The results of this study indicate that Financial Perspective has a significant influence on company performance, Customer Perspective has a significant influence on company performance, Perspective Internal Business Processes have a significant influence on company performance, Learning \& Growth Perspective has a significant influence on company performance, and Learning \& Growth Perspective has the largest coefficient of determination. It can be concluded that the implementation of the Balanced Scorecard affects the performance of the company PT Gramedia Asri Media.
\end{abstract}

Keywords : Balanced Scorecard, Company Performance, Retail

\begin{abstract}
Abstrak : Penelitian ini bertujuan untuk mengetahui pengaruh implementasi scorecard yang dibagi ke 4 perspektif yaitu financial perspective, Customer Perspective, Internal Business Processes Perspective, dan Learning \& Growth Perspective terhadap kinerja perusahaan PT. Gramedia Asri Media. PT Gramedia Asri Media merupakan perusahaan yang bergerak dalam industri retail. Metode yang dipakai dalam penelitian ini adalah survei dengan jenis penelitian asosiatif. Analisis dimulai dengan mengumpulkan data yang diperoleh dari hasil sebaran kuesioner dengan unit analisis yang dituju yaitu store manager PT Gramedia Asri Media. Data yang didapat diolah dengan menggunakan aplikasi SPSS 20 dengan teknik analisis regresi sederhana dan regresi berganda. Hasil penelitian ini menunjukkan bahwa Financial Perspective mempunyai pengaruh yang signifikan terhadap kinerja perusahaan, Customer Perspective mempunyai pengaruh yang signifikan terhadap kinerja perusahaan, Internal Business Processes Perspective mempunyai pengaruh yang signifikan terhadap kinerja perusahaan, Learning \& Growth Perspective mempunyai pengaruh yang signifikan terhadap kinerja perusahaan, dan Learning \& Growth Perspective memiliki nilai koefisien determinasi terbesar. Dapat disimpulkan bahwa implementasi Balanced Scorecard berpengaruh pada kinerja perusahaan PT Gramedia Asri Media.
\end{abstract}

Kata Kunci : Balanced Scorecard, Kinerja Perusahaan, Retail 


\section{LATAR BELAKANG}

Tingginya persaingan industri ritel, membuat pengusaha retail di Indonesia harus memutar otak agar tidak kalah saing dan berguguran seperti di sepanjang tahun 2017. Terdapat beberapa toko retail yang terpaksa harus menutup beberapa gerainya di akhir tahun 2017, antara lain : Department Store Retail (Matahari Department Store, Ramayana, Lotus, Debenhams, GAP), Convenience Store Retail (Seven Eleven).

PT Gramedia Asri Media (PT GAM) merupakan perusahaan yang bergerak di Industri Retail. PT GAM merupakan bagian dari unit usaha Group of Retail \& Publishing anak perusahaan Kompas Gramedia. Pada tahun 1970 merupakan awal mula nama Gramedia di kenal sebagai toko buku di Jakarta Barat. PT GAM dengan semangatnya mewujudkan Performance Management menggunakan metode Balance Scorecard untuk mengukur kinerja dan pencapaian perusahaan. PT GAM memiliki Visi dan memiliki road map yang di berikan rutin per tahun oleh corporate, yaitu Kompas Gramedia sebagai holding company. Hal tersebut tentu selaras dengan kegiatan rutin yang dilakukan setiap tahunnya oleh masing - masing unit usaha yaitu cascading. Cascading merupakan penurunaan strategi objektif dari tingkat unit bisnis sampai ke tingkat divisi dalam suatu perusahaan. Menurut Lin et al. (2014), Balance Scorecard secara formal didefinisikan sebagai pendekatan multidimensional untuk mengukur kinerja manajemen melalui hubungan antara strategi organisasi dan kinerja operasional.

Menurut Kaplan \& Norton (1996) penggunaan Balanced Scorecard adalah sebagai sistem manajemen strategis, kinerja keuangan sebagai ukuran keberhasilan. Balanced Scorecard menambahkan langkah-langkah strategis non-keuangan hal ini digunakan agar lebih fokus pada kesuksesan jangka panjang. Balanced Scorecard telah berkembang selama bertahun-tahun dan sekarang dianggap sebagai sistem manajemen strategis yang terintegrasi.

Dalam penggunaannya, Balanced Scorecard dapat terukur dengan adanya Key Performance Indicator (KPI). Oleh karena itu, suatu proses akan dinilai secara kuantitatif. Dalam perwujudannya, terdapat KPI yang dimiliki oleh 117 toko yang ada pada PT GAM. Dalam pencapaiannya, indeks selama tahun 2015 - 2017 tertera pada grafik di bawah ini. Bersumber dari Departemen Strategic Management Office PT GAM.

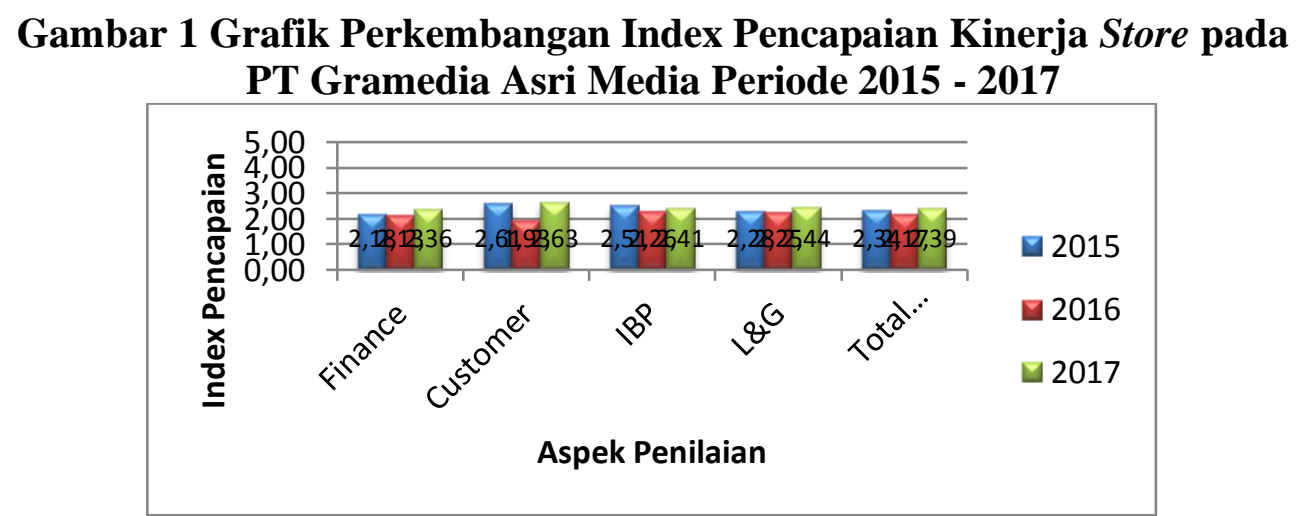

Sumber : SMO Department - Group of Retail \& Publishing

Dari Gambar 1.3 menunjukan perkembangan index pencapaian yang di raih 117 store di PT GAM. Dari perspektif financial terlihat terdapat kenaikan yang tidak terlalu signifikan di tahun 2017. Dari perspektif Customers tahun 2016 merupakan pencapaian terendah. Dari perspektif internal business processes terdapat kenaikan yang tidak sigifikan di tahun 2017. Dari Learning \& Growth terdapat kenaikan yang tidak signifikan di tahun 2017. Untuk total keseluruhan kinerja mengalami penurunan pada tahun 2016 dengan indeks 2.17, tetapi semakin membaik di tahun 2017 naik 0.22 poin ke angka 2.39. Perlu diketahui bahwa indeks maximal yang dapat dicapai adalah sebesar 5.00. Dari grafik tersebut menunjukan pencapaian index kinerja pada 117 store PT Gramedia Asri Media tidak memiliki nilai yang cukup baik dari 
tahun ke tahun di bandingkan nilai maksimal yang bisa diperoleh oleh PT GAM. Adapun tujuan dari penelitian yaitu untuk mengetahi Untuk mengetahui pengaruh financial perspective terhadap kinerja perusahaan pada PT Gramedia Asri Media. Untuk mengetahui pengaruh customers perspective terhadap kinerja perusahaan pada PT GAM. Untuk mengetahui pengaruh internal business processes perspective terhadap kinerja perusahaan pada PT Gramedia Asri Media. Untuk mengetahui pengaruh learning \& growth perspective terhadap kinerja perusahaan pada PT Gramedia Asri Media. Oleh karena itu peneliti tertarik untuk melakukan penelitian dengan judul "Pengaruh Implementasi Balanced Scorecard terhadap Kinerja Perusahaan Pada PT Gramedia Asri Media."

\section{TINJAUAN PUSTAKA}

Definisi Balanced Scorecard secara singkat adalah suatu sistem manajemen strategis untuk mengukur kinerja secara utuh dari aspek financial \& Non financial; mengkomunikasikan visi, strategi dan sasaran kepada stakeholders; mengelola implementasi strategi (Kaplan, 2010). Peta strategi menggambarkan proses perubahan aset tidak berwujud menjadi hasil keuangan serta pelayanan kepada pelanggan. Hal inilah memudahkan eksekutif untuk mendesain kerangka kerja dalam menggambarkan dan mengelola strategi, yang dibagi menjadi 4 perspective, yaitu :

- Financial Perspective mengukur tujuan keuangan perusahaan untuk menciptakan nilai pemegang saham yang berkelanjutan serta mendukung sub tujuan dalam hal pertumbuhan pendapatan, produktivitas, dan manajemen risiko. Tujuan dari perspektif ini adalah untuk menjawab "bagaimana seharusnya organisasi bertanggung jawab kepada pemegang saham (Shareholders)?" (Kaplan, 2010).

- Customers Perspective mengukur tercapainya keinginan pelanggan, tercermin dari aspek memuaskan pelanggan, penguasaan pelanggan dan mempertahankan pelanggan. Tujuan dari perspektif ini adalah untuk menjawab "bagaimana seharusnya organisasi bertanggung jawab kepada Customers/Stakeholders?" (Kaplan, 2010).

- Internal Business Processes Perspective mengukur kinerja organisasi dalam hal efektivitas dan efisiensi proses pada prosedur internal. Tujuan dari perspektif ini adalah untuk menjawab "proses bisnis apa yang harus dilakukan oleh organisasi?" (Kaplan, 2010).

- Learning \& Growth Perspective mengukur pertumbuhan organisasi untuk mencapai pengembangan karyawan, sistem informasi dan keselarasan strategi. Tujuan dari perspektif ini adalah untuk menjawab "bagaimana organisasi akan mempertahankan kemampuannya untuk berubah dan berkembang?" (Kaplan, 2010).

Peneliti melakukan kajian penelitian terdahulu yang memiliki variabel yang menyerupai penelitian ini. Hasil yang didapat adalah sebagai berikut:

- Menurut Sahiti (2016), Balanced Scorecard telah berkontribusi untuk meningkatkan kinerja dan profitabilitas untuk bisnis yang telah mengadopsi model ini.

- Menurut Ridwan et al (2013), Hasil dari penelitian ini menunjukkan bahwa meskipun kebijakan untuk mengadopsi scorecard secara hukum dipaksakan dari pihak luar, pengaruh dari Balanced Scorecard memiliki dampak yang signifikan terhadap struktur organisasi, operasi serta keseluruhan kinerja organisasi.

- Menurut Shukria et al (2015), Temuan utama mengungkapkan bahwa mayoritas rumah sakit swasta yang mengadopsi Balanced Scorecard sangat tersentralisasi dan formal. Dengan demikian, ada hubungan yang sah dengan peningkatan kinerja pada sektor proses bisnis internal, layanan kualitas pasien, keselamatan dan kepuasan konsumen, pembelajaran dan pertumbuhan organisasi, dan keuangan. 
- Menurut Strohhecker (2007), pengaruh Balanced Scorecard Management pada implementasi strategi kinerja perusahaan. Hasil dari penelitian ini menunjukkan bahwa Grup $B S C$ memiliki dampak yang positif terhadap kinerja perusahaan.

Berdasarkan tinjauan pustaka diatas, dapat digambarkan kerangka pemikiran mengenai pengaruh implementasi Balance Scorecard terhadap Kinerja Perusahaan, sebagai berikut:

Gambar 2 Kerangka Pemikiran

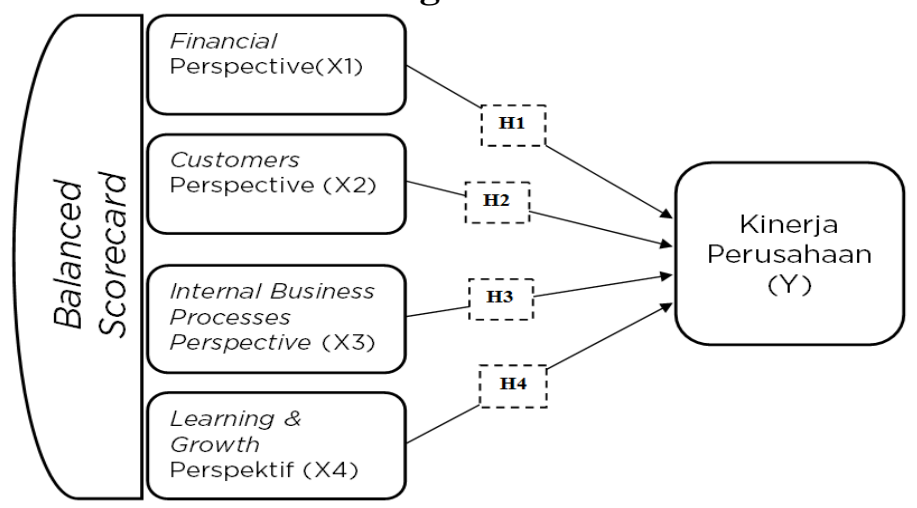

Sumber : Peneliti, 2018

\section{METODE PENELITIAN}

Penelitian ini bersifat deskriptif kuantitatif, yaitu menjelaskan hubungan antar variabel dengan menganalisis data numerik (angka) menggunakan metode statistic melalui pengujian hipotesa. Metode penelitian yang digunakan adalah metode survey crossectional yaitu suatu penelitian untuk mempelajari dinamika korelasi antara faktor - faktor risiko dengan efek yang ditimbulkan dengan cara pendekatan, observasi, atau pengumpulan data sekaligus pada suatu saat (point time approach.)

Data yang dibutuhkan di dalam penelitian ini adalah data kuantitatif yang berupa angkaangka. Sumber datanya adalah primer dimana data didapat langsung dari karyawan yang dijadikan responden, melalui penyebaran kuesioner. Semua sumber data yang digunakan adalah data primer yang didapat langsung dari karyawan melalui penelitian langsung terhadap objek khususnya pada karyawan yang menjabat sebagai store manager. Data didapat dari perusahaan dimana penelitian dilakukan di PT. Gramedia Asri Media.

Jumlah populasi sebanyak 117 orang. Populasi tersebut akan diolah menjadi sampel, Menurut Sarjono \& Julianita (2011:21) Sampel adalah bagian dari populasi yang dipercaya dapat mewakili karakteristik populasi secara keseluruhan. Simple Random Sampling dikatakan simple (sederhana) karena pengambilan anggota sampel dari populasi dilakukan secara acak tanpa memperhatikan strata yang ada dalam populasi tersebut Sugiyono (2011:64). Dengan menggunakan rumus slovin, sampel yang diperoleh adalah 91 orang.

Data yang didapatkan melalui proses kuesioner dilanjutkan dengan mengubah menjadi skala likert yang berarti Sangat Setuju $(S S)=5$; Setuju $(S)=4$; Kurang Setuju $(K S)=3$; Tidak Setuju $(\mathrm{TS})=2$; Sangat Tidak Setuju $(\mathrm{STS})=1$. Dari data yang sudah dikumpulkan dan diproses menjadi tabel, data diuji dengan berbagai pengujian menggunakan aplikasi bantu SPSS v.20. Uji yang dilakukan yaitu uji validitas, uji reliabilitas, uji normalitas. Jika semua data sudah memenuhi standar Dasar Pengambilan Keputusan (DPK) dapat lanjut ke tahap berikutnya yaitu uji regresi dan uji korelasi.

\section{HASIL DAN KESIMPULAN}

Dari hasil penyebaran kuesioner kepada 91 sampel Store Manager pada PT Gramedia Asri Media, didapatkan hasil penelitian yang telah diolah dengan program SPSS v.20. Ditampilkan pada table di bawah ini. 
Tabel 2 Ringkasan Hasil Pengolahan Data

\begin{tabular}{|l|l|l|}
\hline \multicolumn{1}{|c|}{ Variabel } & \multicolumn{1}{|c|}{ Korelasi } & $\begin{array}{c}\text { Koefisien } \\
\text { Determinasi }\end{array}$ \\
\hline $\mathbf{X}_{\mathbf{1}} \rightarrow \mathbf{Y}$ & 0,505 & $\mathbf{2 5 , 5 \%}$ \\
\hline $\mathbf{X}_{\mathbf{2}} \rightarrow \mathbf{Y}$ & 0,564 & $\mathbf{3 1 , 8 \%}$ \\
\hline $\mathbf{X}_{\mathbf{3}} \rightarrow \mathbf{Y}$ & 0,459 & $\mathbf{2 1 , 1 \%}$ \\
\hline $\mathbf{X}_{\mathbf{4}} \rightarrow \mathbf{Y}$ & 0,613 & $\mathbf{3 7 , 5 \%}$ \\
\hline $\mathbf{X}_{\mathbf{1}}, \mathbf{X}_{\mathbf{2}}, \mathbf{X}_{\mathbf{3}}, \mathbf{X}_{\mathbf{4}} \rightarrow \mathbf{Y}$ & 0,749 & $\mathbf{5 6 , 2 \%}$ \\
\hline
\end{tabular}

Sumber: Hasil Pengolahan Data, 2019

\section{Analisis Regresi Sederhana}

- Pembahasan Financial Perspective (X1)

Variabel Financial Perspective $\left(\mathrm{X}_{1}\right)$ memberikan kontribusi sebesar 25,5\% terhadap variabel kinerja perusahaan (Y). Artinya $25,5 \%$ dari variabel Financial Perspective $\left(\mathrm{X}_{1}\right)$ yang memengaruhi variabel kinerja perusahaan. (Y). Sisanya sebesar 74.5\% dipengaruhi oleh variabel lain. Peneliti menyadari bahwa indikator "Improve Cost Structure" memiliki total bobot tertinggi dimana perusahaan perlu mempertahankan \& meningkatkan pengolahan struktur pengolahan biaya.

- Pembahasan Customer Perspective (X2)

Variabel Customer Perspective $\left(\mathrm{X}_{2}\right)$ memberikan kontribusi sebesar 31,8\% terhadap variabel kinerja perusahaan (Y). Artinya $31,8 \%$ dari variabel Customer Perspective $\left(\mathrm{X}_{2}\right)$ yang memengaruhi variabel kinerja perusahaan. (Y). Sisanya sebesar 68,2\% dipengaruhi oleh variabel lain. Peneliti menyadari bahwa indikator "Service" memiliki total bobot tertinggi dimana perusahaan perlu mempertahankan \& meningkatkan standar layanan kepada konsumen.

- Pembahasan Internal Business Processes Perspective (X3)

Variabel Internal Business Processes

Perspective (X3) memberikan kontribusi sebesar 21,10\% terhadap variabel kinerja perusahaan (Y). Artinya 21,10\% dari variabel Internal Business Processes Perspective (X3) yang memengaruhi variabel kinerja perusahaan (Y). Peneliti menyadari bahwa indikator "Environment" memiliki total bobot tertinggi dimana perusahaan perlu mempertahankan \& meningkatkan keamanan dalam area kerja.

- Pembahasan Learning \& Growth Perspective (X4)

Variabel Learning \& Growth Perspective (X4) memberikan kontribusi sebesar 37,50\% terhadap variabel kinerja perusahaan (Y). Artinya 37,5\% dari variabel Learning \& Growth Perspective (X4) yang memengaruhi variabel kinerja perusahaan. (Y). Sisanya sebesar 62,5\% dipengaruhi oleh variabel lain. Dalam analisis regresi sederhana, Learning \& Growth Perspective merupakan variabel dengan koefisien determinasi terbesar, sehingga Learning \& Growth Perspective merupakan variabel terbesar yang dapat mempengaruhi kinerja perusahaan. Peneliti menyadari bahwa indikator "The Skills" memiliki total bobot tertinggi dimana perusahaan perlu mempertahankan \& meningkatkan kualitas karyawannya.

\section{Analisis Regresi Berganda}

- Pembahasan Financial Perspective (X1), Customer Perspective (X2), Internal Business Processes Perspective (X3), Learning \& Growth Perspective (X4) terhadap Kinerja Perusahaan (Y)

Ke empat variabel secara simultan memberikan kontribusi sebesar 56,2\% terhadap variabel Kinerja Perusahaan (Y). Artinya jika variabel Financial Perspective (X1), Customer Perspective (X2), Internal Business Processes Perspective (X3), Learning \& Growth Perspective (X4) diterapkan di dalam perusahaan secara simultan, maka 56,2\% akan 
memengaruhi variabel Kinerja Perusahaan (Y). Sisanya sebesar 43,8\% dipengaruhi oleh variabel lain.

\section{Kesimpulan}

Dari penelitian ini, dapat ditarik beberapa simpulan, yaitu :

1. Terdapat pengaruh Financial Perspective terhadap kinerja perusahaan pada PT Gramedia Asri Media.

2. Terdapat pengaruh Customer Perspective terhadap kinerja perusahaan pada PT Gramedia Asri Media.

3. Terdapat pengaruh Internal Business Processes Perspective terhadap kinerja perusahaan pada PT Gramedia Asri Media

4. Terdapat pengaruh Learning \& Growth Perspective terhadap kinerja perusahaan pada PT Gramedia Asri Media

5. Terdapat pengaruh implementasi Balanced Scorecard terhadap kinerja perusahaan pada PT Gramedia Asri Media.

\section{DAFTAR PUSTAKA}

Kaplan, R. S., \& Norton, D. P. (1996). Balanced Scorecard: Transaltion Startey Into Action. Boston: Harvard Business School Press.

Kaplan, R. S. (2010). Conceptual Foundations of the Balanced Scorecard. Harvard Business School Accounting \& Management Unit Working Paper No.10-74.

Lin, Z., Yu, Z., \& Zhang, L. (2014). Performance Outcomes of Balanced Scorecard Application in Hospital Administration in China. China Economic Review, 30, 1-15.

Ridwan, H., An, Y., \& Fahmid, M. I. (2013). The Impact of the Balanced Scorecard on Corporate Performance : The Case of an Australian Public Sector Enterprise. International Business Research, Vol 6 No 10.

Sarjono, H., \& Julianita, W. (2011). SPSS Vs Lisrel: Sebuah Pengantar, Aplikasi Untuk Riset. Jakarta: Salemba Empat

Sahiti, Arben \& Ahmeti, Skender \& Sahiti, Arbana \& Aliu, Muhamet. (2016). The Impact of Balanced Scorecard on Improving the Performance and Profitability of the Implementing Companies. Mediterranean Journal of Social Sciences. 10.5901/mjss.2016.v7n4p60.

Shukria, N. F. Moh., \& Ramlia, A. (2015). Organizational Structure And Performances Of Responsible Malaysian Healthcare Providers: A Balanced Scorecard Perspective.Procedia Economics And Finance 28, 202 - 212.

Sugiyono. (2011). Metode Penelitian Kuantitatif, kualitatif dan R \& D. Bandung: Alfabeta 